\title{
USE OF GREY MONGOOSE HERPESTES LANKA. WROUGHTON FOR DETECTING NARCOTIC DRUGS
}

\author{
V. RAVINDRAN
}

Department of Animal Science, University of Peradeniya, Peradeniya.

\begin{abstract}
AND
S.B.U. FERNANDO

National Zoological Gardens, Dehiwela.

(Date of receipt : 16 Altgust 1993)

(Date of acceptance : 18 December 1993)

Abstract: The feasibility of using the Sri Lankan grey mongoose : Herpestes lanka Wroughton for detecting narcotics was evaluated. The results demonstrate that it is feasible to train grey mongooses to sniff narcotic drugs in 8-12 weeks. They are easily tamed and training was more effective with younger animals. Some observations on the behaviour and feed preferences of grey mongoeses are also reported.
\end{abstract}

\section{INTRODUCTION}

In Sri Lanka, the abuse of a variety of narcotic drugs is on the increase. Their ready availability stems from an increased drug traffic. Much of the drugs, particularly hashish and heroin, are reportedly brought in by couriers who travel by air from countries of the 'golden crescent' (consisting of Afghanistan, Pakistan and Iran). It is believed that Sri Lanka is increasingly used as a transit point for the traffickers, largely because of relative obscurity of Katunayake Airport. ${ }^{1}$

The Sri Lanka Police have trained German Shepherd dogs (imported from Austria and West Germany) that are currently used to detect drugs by sniffing. However these are expensive animals to maintain, costing over US \$200 per month per dog. There is a religious impediment to the use of dogs to detect drugs. Moslems regard dogs as unclean and lowly and, are outraged when the animals sniff through their luggage and personal effects. To avoid unpleasantness, the dogs covertly sniff the luggage of passengers outside the arrival hall. Since the 'golden crescent' countries are moslem countries, this perhaps constitutes the major practical hurdle to anti-narcotic efforts.

The feasibility of training an inoffensive and less expensive indigenous animal is therefore of interest to the local law enforcement agencies. The senior Sri Lankan officials involved in anti-narcotic operations were unanimous in their choice of the common grey mongoose Herpestes lanka Wroughton. This is because of the popular belief in the olfactory acuity of the animal, though this had never been shown under controlled conditions. 
Four species of mongooses are found in Sri Lanka. ${ }^{2,3,4}$ They are: 1) The common Sri Lankan grey mongoose Herpestes lanka Wroughton. ii) The ruddy mongoose $H$. smithii zeylanicus Thomas. iii) The brown mongoose $H$. flavidens Kelaart. iv) The stripe-necked mongoose $H$ : vitticollis Bennett.

Of the four species, the grey mongoose is the most common and easily domesticated. ${ }^{5}$ The other species are for est dwellers that are rarely seen in captivity. For this reason, the present project was primarily concerned with the training of grey mongooses in the detection of narcotic drugs. Grey mongooses are easily tamed when young. They are intelligent and reliable pets and follow to heel like a dog. They are small animals that are inexpensive to maintain.

\section{METHODS AND MATERIALS}

\section{General Details}

The project was located at the National Zoological Gardens, Dehiwela. Eighteen mongooses were purchased or trapped for the project between August 1987. and March 1988. The history of these 18 mongooses is summarized in Table 1. Of these, eight (all adult animals) could not be tamed and were released. The animals were individually housed in cages (approximately $0.7 \mathrm{~m}^{2}$ ) arranged against the wall of a semi-open building. The cages provided ample space for the play movement. Sanitary conditions were maintained throughout. The mongooses were fed twice a day. The morning meal consisted of half an egg (boiled) and the evening meal of $300 \mathrm{~g}$ uncooked beef. About $100 \mathrm{~g}$ fresh fruits (banana, papaw or mango) was offered once a week. This diet was sufficient to maintain the animals in a healthy condition. Clean water was made available at all times.

All animals were immunized against rabies, since the mongooses are known carriers of this disease. ${ }^{6,7}$ Individual records were maintained for each animal and observations on their behavioural patterns made. The mongoose in the wild is more diurnal than nocturnal in its habits though it may be also seen about in the heat of the day. ${ }^{5}$ In captivity, however, they were observed to be active all hours of the day. The interesting feature directly relevant to the project, was their utmost curiosity in their surroundings, typified by sniffing and prying into corners and crevices.

The feed preferences of mongooses in captivity were also studied. The captive animals were offered a variety of feeds to see whether these would be readily accepted as feeds. It was observed that the mongoose rarely refuses anything edible. But a definite preference was observed towards animal products (mealy worms, day-old chicks, meat, egg, liver and milk). Plant products (fruits, bread, cooked rice, roots greens) were consumed, but less readily accepted. 
Table 1: Histories of the animals maintained by the project.

\begin{tabular}{|c|c|c|c|}
\hline $\begin{array}{l}\text { Type of } \\
\text { mongoose }\end{array}$ & Sex & $\begin{array}{l}\text { Approximate } \\
\text { age at entry }\end{array}$ & Remarks \\
\hline Ruddy & Male & 8 months & $\begin{array}{l}\text { Tamed; started on training; but turned aggressive } \\
\text { later and had to be taken off training; handled } \\
\text { only by the handler. }\end{array}$ \\
\hline Grey & Male & 6 months & Tamed; successfully trained. \\
\hline Grey & Male & 6 months & Tamed; successfully trained. \\
\hline Grey & Male & Adult & Could not be tamed; released from the project. \\
\hline Grey & Male & Adult & Could not be tamed; released from the project. \\
\hline Grey & Male & Adult & Could not be tamed; released from the project. \\
\hline Grey & Male & Adult & Could not be tamed; released from the project. \\
\hline Grey & Female & Adult & Could not be tamed; released from the project. \\
\hline Grey & Female & Adult & Could not be tamed; released from the project. \\
\hline Grey & Female & 8 months & $\begin{array}{l}\text { Tamed; successfully trained; but subsequently } \\
\text { became 'disinterested' and dropped from the } \\
\text { training. }\end{array}$ \\
\hline Grey & Female & 3 months & $\begin{array}{l}\text { Tamed; successfully the best trained animal; but } \\
\text { died suddenly; reasons unkonwn }\end{array}$ \\
\hline Grey & Male & Adult & Could not be tamed; released from the project. \\
\hline Grey & Male & Adult & $\begin{array}{l}\text { Could not be completely tamed; released from the } \\
\text { project }\end{array}$ \\
\hline Grey & Male & 10 months & Tamed; not trained due to lack of handlers \\
\hline Grey & Female & $11 / 2$ months & $\begin{array}{l}\text { Tamed; successfully trained; one of the best } \\
\text { trained animals. }\end{array}$ \\
\hline Brown & Female & 2 months & $\begin{array}{l}\text { Tamed; training not attempted due to lack of } \\
\text { handlers. }\end{array}$ \\
\hline Grey & Male & 6 months & Tamed; but not trained due to lack of handlers. \\
\hline Grey & Female & 2 months & Tamed; successfully trained. \\
\hline
\end{tabular}

With adult animals, measurements were also taken to characterize the body conformation. The males of the species are considerably larger than the females (Table 2). The average adult body weight was $1600 \mathrm{~g}$ for males and $1050 \mathrm{~g}$ for females. The adult size was reached after $15-18$ months.

\section{Training of Mongooses}

During the early stages, the non-availability of canine training manuals in Sri Lanka hindered the development of an appropriate training module for the mongooses. In the absence of this much-needed information, the methodology outlined herein was developed and refined on a 'trial and error' basis. 
Open outdoor areas were first used for training purposes. However, it was observed that the older mongooses, used during the early stages of the project, were easily disturbed by any "foreign" noises. For this reason, the training was later shifted indoors where a more "controlled" environment could be provided. This problem was not observed with younger mongooses. Two handlers, having previous working experience with animals, were selected for the training of mongooses. They were also responsible for the day-to-day care and management of the mongoose unit.

Table 2: Body measurements of adult grey mongooses.

\begin{tabular}{lcc}
\hline & Male $^{*}$ & Female $^{* *}$ \\
\hline Length of head, cm & 12.0 & 10.8 \\
Length of body, cm & 67.0 & 58.8 \\
Length of tail, cm & 30.0 & 28.0 \\
Total body length, cm & 109.0 & 97.5 \\
Length of forelimb, cm & 13.3 & 12.0 \\
Length of hindlimb, cm & 13.5 & 13.0 \\
Length of ear, cm & 3.0 & 3.0 \\
\hline
\end{tabular}

- Average of 5 specimens

-* Average of 4 specimens

\section{Narcotic Material}

About $10 \mathrm{~g}$ of heroin were obtained periodically from the Police Narcotics Bureau. The drug was released in batches of $2 \mathrm{~g}$ to the custody of a technician who issued it to the handlers during the training sessions. This amount was found sufficient for the training of mongooses. The heroin was secreted in paper or polythene in the initial stages, but this was subsequently stitched into perforated cloth bags for safety reasons.

\section{Training Methodology}

The traning programme involved four phases:

1. Establishment a rapport between the handler and the mongoose. The handlers were required to spend few hours a day with the animals and to take them out on a leash. It was observed that mongooses, like the dogs, respond better when commanded by one person. They were disturbed and agitated when handled by more than one handler.

2. Once the relationship between the man and the animal was established, a "toy" was given and the game of retrieving the "toy" was started. An empty plastic hypoder- 
mic syringe ( $75 \mathrm{~mm}$ long and $15 \mathrm{~mm}$ diameter) was used as the "toy". This was a suitable size for the mongoose to hold in its mouth.

In the initial stages, the retrievement of the toy involved the sense of sight rather than the sense of smell. The toy was thrown or visibly hidden, and the command "find" (preceded by the name of the animal) was given. The objective was to condition the mongoose to perform a search. The animal was continuously encouraged by verbal commands. Once the toy was found, lavish verbal ("good boy/girl") and physical (picking up the animal and stroking) praises were given.

For the first two mongooses trained, a food reward (mealy worms) was offered whenever the toy was retrieved. The food reward was later omitted when it was found that mongooses continue to respond to the toy even without this reward. At one point, the mealy worms were placed inside the toy and the toy was hidden. The animals were able to successfully find the toy (with the mealy worm), irrespective of the hiding place. This gave us the first confirmation of the olfactory acuity of the mongoose.

3. As the mongoose's interest in the toy increased, the heroin was introduced into the toy. In essence, this was a typical "classical conditioning" in which the toy (an unconditional stimuli) and the narcotic smell (conditional stimuli) were paired together. The heroin smell was initially neutral; through repeated reinforcements, the mongooses were trained to associate it with the toy. The objective of the exercise was to train the mongooses to respond to the heroin in a manner similar to the toy. No food reward was involved in this kind of training. The only reward was praise.

Within two weeks of intensive training (of about three hours per day), the mongooses started to elicit responses to heroin. The toy was then gradually removed from the training and the animals were found to respond well to heroin alone. That they can differentiate and sense the smell of heroin was clearly established at this time.

The ability of the handler to read the signs shown by his animal became critical at this stage. In the initial stages, the handler knew where the heroin was hidden so that he could learn the responses by which the animal indicates the "find". The mongooses were observed to indicate a detection in the following ways: scratching around the location, change in body posture and sudden alertness. Once the handler was familiar with these signs, the training proceeded onto the next stage where the handler had no prior knowledge of the hiding place.

Care was taken to give a rest period to the animal (and the handler) lest the animal may become disinterested. Although most mongooses were able to keep 
their concentration on search for long periods, about 20 minutes of search appeared optimal. Thereafter, the mongoose is best withdrawn from the search to recover.

4. At the final stages, the concealment of heroin was made gradually more difficult. It was hidden in wastepaper baskets, drawers, containers and suitcases. At this time, the animals reached their optimal performance levels.

\section{RESULTS AND DISCUSSION}

Of the ten tamed animals maintained by the project, seven were successfully trained (The remaining three could not be trained due to lack of handlers). Of these seven, two lost "interest" after sometime (Table 1) and had to be taken off the training; another died after being trained to optimal performance. Thus the success rate can be considered high.

It was found that 8-12 weeks is enough to train the "right type" of mongoose in narcotic detection. We observed that the training.was more effective, quicker and easier when started young. When tamed and trained at a younger age (perferably less than three months of age), the animals were more friendly and less disturbed by the presence of strangers and other animals. These animals, when familiarized at an early stage, showed no fear responses to extraneous noises.

The initial phase of the training programme was designed to "teach" the commands. We found that it was not possible to train mongooses to obey commands to the same extent as dogs. The only command which the mongooses learnt was "find".

The inquisitive nature and the inherent sniffing habit of mongooses make them "ideal" animals for a training of this nature. Being small animals, their main advantage arises from the low maintenance costs. It was estimated that a mongoose could be maintained for less than Rs 500 (US $\$ 10$ ) per month.

Frequent changes of working environment and situations are suggested, since familiar training situations tend to create boredom. Male mongooses appeared to be less suitable for training. They tended to be more independent and sometimes even tried to dominate the handler by becoming aggressive. Furthermore, they tended to become restless at sexual maturity. Two males had a complete "lapse" of imprinted training memory; their attention tended to lag quickly and eventually had to be taken off the training. The exact cause for this "restlessness" after puberty is unclear. Such an effect was not observed with females.

The domestication of dogs dates back to over 10,000 years and during this time they have been selectively bred for various purposes. In contrast mongooses are wild 
animals which is reflected by the aggressiveness and "built-in" fear of untamed animals. This limitation can be overcome, at least partly, through captive breeding of mongooses. It is suggested that captive breeding and selection are important aspects to be considered if further use of mongooses is envisaged. Captive breeding of mongooses have never been attempted; however, they are known to breed inside houses. 5 If a large selection variabiligy can be given, it may be possible to select "suitable" types with good temperament and alertness.

The careful choice of the handler is possibly equally important. Our experience showed that the handler is more likely to let down his mongoose than vice - versa. It is very important that he likes to work with animals, has the ability to motivate the animal, be perceptive enough to understand the body language of the animal and keep his concentration for long periods of time.

The results of the present project confirmed the olfactory acuity of grey mongooses under controlled conditions. The major finding of the project, that grey mongooses can be trained to detect narcotic drugs, was confirmed by an independent evaluation by a consultant to the Bureau of the International Narcotic Matters of the U.S. State Department. ${ }^{8}$ The trained mongooses were not tested under operational situations but there is little reason to anticipate failure. No attempt was made in the present project to compare trained mongooses and dogs. However the impression obtained was that mongooses might be less efficent than dogs at detecting drugs. The overall results of this project, however, favour further evaluation and use of grey mongooses for detecting narcotics.

\section{Acknowledgement}

The study was suppported by a grant from the Bureau of International Narcotics Matters of the U.S. State Dapartment, Washington, D.C. Appreciation is extended to the Ministry of State of Sri Lanka for permission to conduct the study at the National Zoological Gardens, the staff of the National Zoological Gardens for care and management of animals, the staff of the American Embassy, Colombo for their cooperaton, to Director, Police Narcotic Bureau, Colombo for the issue of narcotic materials needed for the training and to Mr: Wijaya Seneviratne, Assistant Superintendent of Police (Kennels), Kandy for sharing his expertise on canine training.

\section{References}

1. Anon (1986). Illicit Drug Trafficking and Drug Abuse in Sri Lanka. Report No. 9. pp. 8. National Dangerous Drugs Control Board, Colombo.

2. Deraniyagala P.E.P. (1984). Some Verterbrate Animals of Ceylon. pp.119. The National Museum of Ceylon. Colombo Museum, Colombo. 
3. Grzimek H.C.D. (1972). Grzimek's Animal Life Encyclopedia: Mammals, Van Nostrand Reinhold Company, New York.

4. Hill J.F. (1980). The mammals of Sri Lanka. Sporia Zeylanica 35: 203-212.

5. Phillips W.W.A. (1985). Mongooses. In: Manual of the Mammals of Ceylon, pp. 176-192. Dalua \& Co. Ltd. London.

6. Nellis D.W., Eichholz N.F., Regan T.W. \& Feinstein C. (1978). Mongoose in Florida. Wildlife Society Bulletin 6: 249-250.

7. Hinton H.E. \& A.M.S. Dunn (1967). Mongoose - Their Natural History and Behaviour, Oliver \& Boyd, London.

8. Hoban I. (1988). Project on the Feasibility of Using Mongooses for Narcotic (Heroin) Detection. Consultant's report submitted to the Bureau of International Narcotic Matters of the U.S. State Department, Colombo. pp. 15. 